\title{
What can consultants expect from the Griffiths report?
}

\author{
DAVID BOLT
}

The individual consultant may well be apprehensive about how the Griffiths report will affect his clinical work. His attitude to the government's plans to reform NHS management (based on the Griffiths proposals) will largely depend on one of two factors. ${ }^{1}$ Does the consultant believe that the deficiencies of the National Health Service are due to inadequate funding and could be cured by additional resources, or does he suspect that much more could be achieved within existing resources if the money was efficiently used? It is fundamental to the Griffiths proposals that extra funds should be diverted to patient care as a result of greater economy in those areas of the service not directly related to clinical activity. It is also implicit, however, that the resources made available for patient care should be used efficiently. Should these two objectives be achieved and the community's genuine health care needs still be conspicuously inadequate, the case for judging the NHS to be underfunded will be greatly strengthened.

While all consultants subscribe-at least in theory-to the view that clinical care should be conducted with the maximum economy compatible with effectiveness, many are anxious about how such terms may be interpreted in future. While they are aware that Mr Roy Griffiths, who chaired the government's NHS management inquiry, frequently rejected any suggestion that his proposals would interfere with clinical freedom, experience has taught them to expect wide discrepancies between the declared intention of any reorganisation and its practical effects. At present, when implementation of the proposals is proceeding at regional health authority level but has started in only a few district authorities, the precise implications for the practising consultant can be only dimly foreseen.

\section{Clinical freedom}

So far the health service has offered consultants an exceptional degree of clinical freedom. They have been able to treat their patients in the way that their judgment dictated, without thought of the cost, which in many other health care systems has been a constantly restricting factor. Despite this, clinical freedom remains a largely philosophical concept because it has inevitably been limited by the availability of resources. If when a consultant sees a patient who in his judgment requires urgent admission to hospital it takes three or four weeks to find that patient a bed then clinical freedom is being curtailed. Indeed, if the current proposals achieve their objective and a larger proportion of total NHS resources flows into clinical care such events may be less common and the consultant's clinical freedom will have been enhanced.

$\mathrm{Mr}$ Griffiths often said that it would manifestly be impossible

\section{Honiton, Devon EX14 0BE}

DAVID BOLT, FRCS, retired consultant surgeon and past chairman of the Central Committee for Hospital Medical Services

Correspondence to: Feniton House, Feniton, Honiton, Devon EX14 OBE. for the district general manager, be he medically qualified or not, to interfere with a doctor's clinical judgment, and in any direct sense this is true. Any directive to an individual consultant about how to treat a specific patient would be so grossly improper and would generate so explosive an outcry-in and outside the profession-that such conduct is inconceivable. Nevertheless, it seems likely that district managers will practise less direct interference by pressing for more of the kind of professional committees that are already at work in some hospitals, discussing and drawing up guidelines for patterns of management of patients with specific conditions. Many hospitals have antibiotic committees, which lay down programmes to preserve the effectiveness of newer antibiotics and discourage the use of unnecessarily expensive drugs when others will be equally effective. Some hospitals print their own pharmacopoeias designed to guide medical staff into using the most economical drugs. Others have theatre users' committees concerned with the economical and efficient use of theatre facilities.

These and many other similar activities can be seen as representing interference with clinical freedom, but few consultants resent such activities because they realise that in a service with finite resources extravagance by one member of the staff may spell shortages for others. In such programmes it has always been understood that if a consultant sees clinical reasons for not adhering to the policy in some individual case he has discretion to vary it. Such a practice must surely continue under the new régime, but it is less clear what authority the district manager will have in relation to the individual consultant who consistently refuses to conform to agreed policies. Many consultants resent extravagance in colleagues, but nothing is usually done about it as the principle of clinical autonomy is regarded as more important than curbing waste. The new district manager may see this differently, but it would be unfortunate if the battle to protect clinical freedom had to be fought to preserve the right to be merely extravagant, however sincerely the consultant concerned believed in the validity of his pattern of practice.

\section{Resource allocation}

Resource allocation has an important indirect effect on clinical freedom, but consultants practise in the real world and they have always accepted that resources must be allocated and have contributed to the discussions that do this. Functional budgeting has not, as yet, become widespread, but where the system operates it is essentially a more precise form of resource allocation. Such budgeting is a fact of life for consultants working in departments such as pathology and radiology, but for consultants in the bedside specialties it has always suffered from a handicap. As major elements such as staff and hotel costs are excluded the cost components that consultants can influence are small. Consequently, I believe that for some time to come the problems of resource allocation will be those concerned with more economical financing of the non-patient services and the proper distribution of the remaining funds among the departments and units providing patient care.

If the promises made in the Griffiths report are to be fulfilled 
the profession will expect to see within a short time of the new district managers starting work clear evidence that extravagance in the non-patient services is really being curbed and that strict budgetary standards are being applied in such departments. When told of the finance available for clinical activities for the coming year consultants have in the past felt little confidence that the kind of critical assessment to which they were subjected had been applied elsewhere. Consultants' confidence in the district manager and their willingness to cooperate with him will be greatly influenced by what they observe in this context.

Whether the new district manager is a doctor or not the process of allocating resources between the many units and departments providing patient care will clearly require specialist advice, as will many other aspects of the day to day running of the district. Consultants are anxious about the machinery for providing this advice, but how the new system will work is unclear. The Griffiths proposals were designed to avoid unsatisfactory compromises and delays in reaching decisions seen by some as an unwelcome characteristic of consensus management. In many places, however, consensus management as practised by district management teams has worked well and consultants would see the elimination of such teams as a disaster. Without it-and no less importantly without the advisory machinery that feeds it-the future looks grimly arbitrary and an official pronouncement is urgently needed.

Distribution of resources remains the most effective tool available to the district manager for influencing patterns of practice. The great danger is, however, that unless sound professional advice is available and absorbed the process of distribution will increasingly become a statistical exercise based on such indicators as throughput - to the serious detriment of standards of clinical practice. The absence of reliable indicators for assessing the quality of patient care is a serious handicap, for quality of care must be set against that favourite official statistic: the numbers of patients treated. Admittedly, most consultants see their work to be of such importance that it should not be curtailed by lack of money, but the NHS would be the poorer if consultants did not have this kind of commitment to their specialties and their patients. Judgments will have to be made, as they are made now, between competing claims, but every consultant must feel that he has had the opportunity, through the mechanism of advisory committees and district management teams, to put the case for his unit and his patients with the greatest possible vigour. For the new system to work it requires an effective and tried arrangement for providing professional advice to the district manager as a prerequisite for a successful health service.

\section{Conditions of employment}

Among the Griffiths report's recommendations was one about which little has recently been heard, the proposed changes in central administration having been largely overshadowed by the problems of implementation at regional and district level. The report proposed that a personnel officer should be among the officers appointed centrally to run the NHS nationally and that his first job should be to review the terms and conditions of employment of all the various staff employed in the service. Assuming that this recommendation has been accepted with the others, nothing will presumably be heard of the matter for at least two years because a new personnel officer could hardly accomplish such a task in less time. The implication for consultants remains as a distant cloud, perhaps no bigger than a man's hand at present, but a cloud that is likely to grow with time. Two particular matters seem likely to attract attention. One is the security of tenure of consultants, whose dismissal for anything less than serious dereliction of duty or major incompetence is almost impossible. My experience is that the Department of Health and Social Security has for a long time believed that it should be possible to dismiss a consultant "in the interests of the service," and I would not be surprised if any review of the terms and conditions came up with some such suggestion.

The second matter concerns accountability. The management changes could well provoke renewed pressure for consultant contracts to be transferred from region to district health authorities, with accountability to the local health authority via the district manager. The latter is, perhaps, of immediate concern because it seems that in some regions the position of the regional medical officer, a vital member of the regional team of officers, is under threat. This must worry all consultants. It says much for the small group of individuals who have filled the regional medical officer posts over the years that consultants so unanimously accept them as the people to whom they are answerable and reject any alternative arrangement. It would be profoundly unfortunate and would raise all sorts of questions about the government's future intentions if the relationship between consultants and their regional medical officers was changed by substantial modification of the latter's status. Indeed, it could well prompt consultants to question their cooperation in the managerial changes.

In the last resort the success or failure of the Griffiths proposals in achieving real improvement in the service for patients will depend-as do many other matters-on personalities. Mr Griffiths himself made the point that for the district manager to succeed he or she must command respect and cooperation among the staff, particularly among clinicians. All doctors will hope that when health authorities make these appointments they will bear this need in mind, even, I suggest, to the extent of having confidential consultations with senior members of the staff. If, however, the objectives of the changesin terms of more resources being directed to services for patients-are to be achieved consultants must cooperate in the exercise and help the new manager in every way possible. I believe that it is in the patients' interests that the objectives of this management reform should be achieved, and the needs of patients must be paramount in the minds of consultants.

\section{Reference}

1 NHS Management Inquiry. Report. London: DHSS, 1983. (Griffiths report.)

\section{THIRTY YEARS AGO}

"It has been universally accepted that group practice by general practitioners is the ideal condition for good medical practice," declared Mr. Aneurin Bevan in opening a new health centre at Harold Hill, near Romford, on October 15. Alderman Mrs. Ball, chairman of the Health Committee of the Essex County Council, who presided at the ceremony, said that it was planned to build similar centres at three other places in the county.

Mr. BEvaN said that as Minister at the time the National Health Service was launched he was compelled to realize that the whole approach to the Health Service was conditional upon acceptance of the fact that there were three elements that went to the making of itnamely, the patient, the doctor, and society-and that these were not always on good terms with one another. Doctors sometimes gave the impression that they thought the other two were there in order to attend upon them. Patients took a slightly grudging attitude to both. Society, represented by the central government and the local authority, had the obligation of providing the apparatus the doctor wished to use for his patients. The doctor was never satisfied that the apparatus was good enough for its purpose, and the central government or local authority was often satisfied that the doctor might not be good enough for the apparatus. "Administration consists in arbitrating between these varying psychologies."

But the best members of the medical profession and the best type of health administrators had put their heads together and asked how the best sort of physical apparatus could be provided to enable the best sort of doctor to use it intelligently on behalf of his patients and to enable him to become a better doctor. To that problem the health centre was the solution. (British Medical fournal 1954 ;ii:152). 


\section{Private practice audit}

The BMA has issued the following statement about private practice audit:

"Representatives of the consultants in Wrexham, the British Medical Association, and the medical defence organisations met the chairman and representatives of chief officers of the Clwyd Health Authority today [15 October]. The meeting was convened to discuss the handling of the advice received by the health authority from the Welsh Office regarding the recent NHS audit into private practice. This advice stated that consultants should be legally compelled to reveal their confidential diaries which include the names and clinical details of patients. The BMA pointed out that the DHSS Welsh Office had initiated this audit and strongly recommended the health authority to refer back to the Welsh Office any further action considered necessary.

"Meanwhile, the BMA will be pointing out to the Secretaries of State that the confidentiality of personal clinical information would be broken and that doctors complying with this direction would be breaching professional ethics should this action be taken. The association will be making proposals to resolve this problem while emphasising that it will never condone corruption or fraud."

\section{Professional witnesses allowances}

In a circular from the Lord Chancellor's department (JC 845 ) courts have been notified of the increased professional witness allowances payable under the Costs in Criminal Cases (Allowances) Regulations, with effect from 1 November 1984. Paragraph 9 of the BMA fees guide has been revised to take account of the new rates and BMA members may obtain a copy from regional offices by quoting reference "Fees 9" and their current membership number.

\section{Junior members forum to meet in Belfast}

The topic for the symposium on the first day of the 1985 junior members forum, 30 March, is "Inequalities in health." The speakers will be:

Sir Douglas Black, president of the BMA 1984-5 and chairman of the DHSS's working party on inequalities in health.

Mr Christopher Patten, MP, parliamentary Under Secretary of State, Northern Ireland Office.

Dr P M Reilly, senior lecturer, Department of General Practice, Queen's University, Belfast.

Dr Ian Jones, community medicine specialist, Fife Health Board.
The second day ( $31 \mathrm{March}$ ) will be devoted to medicopolitics. One of the BMA's senior medicopoliticians will address the meeting, and there will be reports from the forum's representatives on the council and the representative body. Motions on any subject

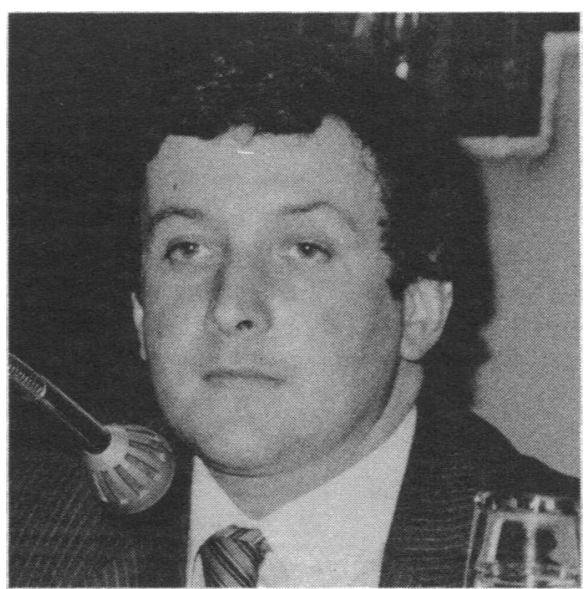

The chairman of the 1985 forum, Dr Michael Donnelly, who is at present a registrar in community medicine in Kettering.

arising from the reports or related to the practice of medicine, which have been tabled during or before the meeting, will be debated and voted on. Resolutions from the forum are referred to the council, the standing committees, and the representative body.

The forum, which is open to members of the BMA who are under 40 and within 12 years of provisional registration, offers an opportunity to exchange ideas and to gain an insight into the affairs of other sections of the profession.

The 1985 forum will be held in Queen's University, Belfast, where overnight accommodation will be available on Friday and Saturday, 29 and 30 March. The meeting will last from 10 am on the Saturday until $330 \mathrm{pm}$ on Sunday 31 March. On the Saturday evening there will be a special dinner with the Northern Ireland divisions.

Further details about the forum, including the procedure for electing representatives, are available from BMA regional offices.

\section{Scotland's doctors have doubts on Griffiths}

In a recent statement the BMA in Scotland says that Scottish doctors have agreed to accept with reservations the concept of general managers in the NHS, but that they have expressed great doubts about whether the best persons for the posts will be appointed.

Details of the Scottish Home and Health Department's proposals to implement the Griffiths plan for managers in Scotland were sent to the BMA's major committees in Scotland for comment.
Dr Alastair Law, chairman of the BMA's Scottish council, commented: "The doctors are aware that the present system of consensus management in the NHS has its drawbacks and the appointment of general managers should result in more speedy and effective decision making. However, we have told the department that the success or otherwise will largely depend on the calibre of those appointed. There could be a great advantage in bringing in 'fresh blood' from outwith the NHS, where there is no suitable internal candidate, despite the problems such managers would face in understanding the complexities of the NHS. The salaries under the present proposals available for these posts will almost certainly discourage persons of high calibre from applying. We are very concerned on this point."

Dr Angus Ford, chairman of the BMA's Scottish Committee for Hospital Medical Services, said: "One major misgiving felt by the hospital consultants is that the recent reorganisation of the health service in Scotland will make it very difficult to implement the Griffiths report at hospital level. We see each individual hospital classified as a unit where clinicians can make a valuable contribution to management. However, the reorganisation has created units which include several hospitals and other institutions. We are seeking urgent discussions with the Department on this matter."

The doctors point out that general managers are to be appointed for five years initially and they wish assurance that if a chief officer of a health board is appointed as manager but is not reappointed after five years then he or she should be able to return to his or her original post on the health board. The doctors also want assurance that they should still have direct access to the Secretary of State, ministers, and the Chief Medical Officer; that medical manpower will continue to be centrally controlled; that the review body system of remuneration of doctors and dentists will continue; that representatives of medical staff will continue to have ready access to health boards at all levels; and that the existing central negotiating machinery will remain.

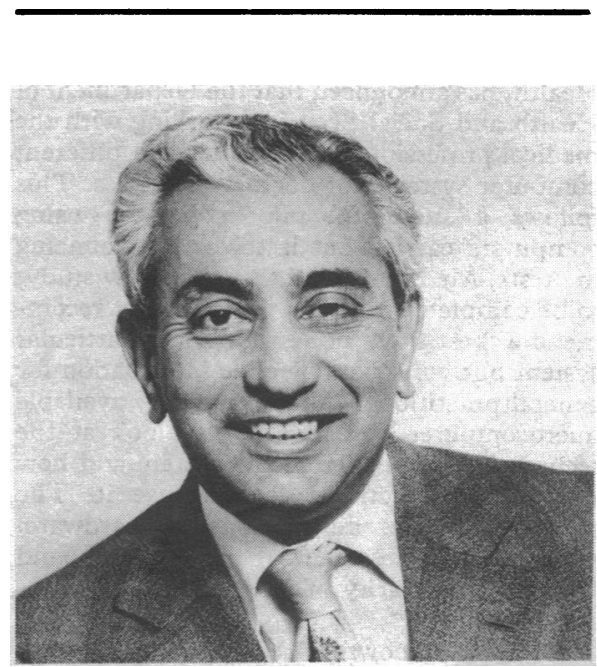

Dr M Hamid Husain, a general practitioner in Rotherham, has been elected chairman of the organisation committee. He succeeds Dr Ralph Lawrence, who has been chairman since 1973. Dr Husain is a member of the BMA council and of the General Medical Services Committee. Dr Mary White was elected deputy chairman. 


\section{Occupational health}

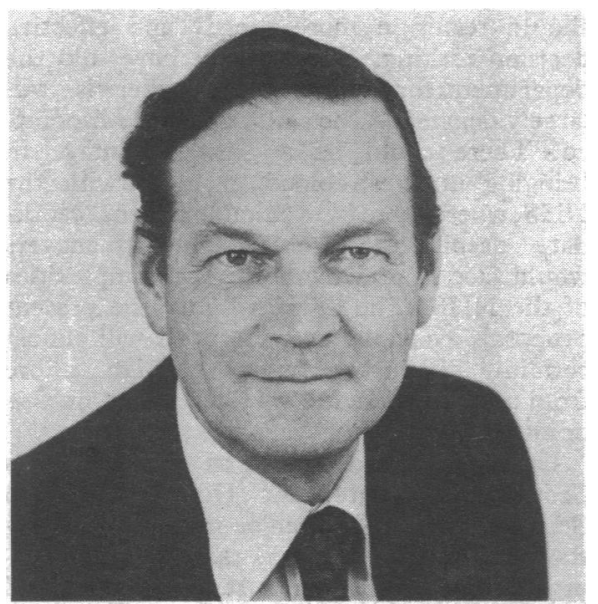

At its meeting on 10 October the occupational health committee re-elected $\mathrm{Dr} W \mathrm{M}$ Dixon as chairman. Dr Dixon is head of the midical services for the John Lewis Partnership. The committee received a progress report from the Chief Medical Officer on the development of occupational health services for NHS staff. The Health and Safety's booklet Guidelines on Occupational Health Services in the Health Service was welcomed and when this has been studied by the General Medical Services Committee and the Central Committee for Hospital Medical Services the occupational health committee will decide whether to make a further approach to the Chief Medical Officer. A response will be made to the report of the House of Lords Select Committee on Science and Technology.

\section{Computer systems for general practitioners to be evaluated}

Mr John Patten, Parliamentary Secretary for Health, has announced that the Department of Health and Social Security, working with the medical profession, is to evaluate 20 different computer systems for doctors' surgeries. This follows a successful pilot study on using computers carried out last year. Announcing the tests, Mr Patten said that "the new study, to be completed within a year, will not recommend a 'best buy,' nor endorse any particular system but will give objective information for general practitioners about currently available microcomputer systems. It will look at the technical performance of the system and how the general practitioner's staff use it. The report will give descriptions of hardware, software, an assessment of performance, and accuracy and clarity of reference documentation."

Companies known to be suppliers of general practitioner microcomputer systems will receive a letter inviting them to participate in the survey in the next few weeks, other interested companies are asked to write to the DHSS.

Meanwhile, the government has published an interim report on its sponsored scheme for microcomputers in general practice.

\section{BMA regional offices}

England Address

Northern RHA

North Western RHA

Trent RHA

Yorkshire RHA

West Midlands

Oxford RHA

Mersey RHA

East Anglia RHA

Wessex RHA and Channel Islands

South Western RHA

South East Thames RHA

North West Thames RHA

North East Thames RHA

South West Thames RHA

Scotland

Wales

Northern Ireland

BMA Northern Regional Office, 4 Eslington Road, Jesmond, Newcastle upon Tyne NE2 4RH. (tel: 0632 818138)

BMA North West Regional Office, 856 Wilmslow Road,

Didsbury, Manchester M20 8RX. (tel: 061434 9231)

BMA Trent Regional Office, Westminster House, 1/7 George Street, Sheffield S1 2PF.

(tel: 0742 21705/0742 753 264)

BMA Yorkshire Regional Office, 51A St Paul's Street,

Leeds LS1 2TE.

(tel: 0532 458745)

BMA Midland Regional Office, 36 Harborne Road, Edgbaston, Birmingham B15 3AJ.

(tel: 021454 5261/4)

BMA Oxford Regional Office,

Cranbrook House,

287 Banbury Road,

Oxford OX2 7JF.

(tel: 0865 59621/2)

BMA Mersey Regional Office,

126 Mount Pleasant, Liverpool L3 5SR

(tel: 051709 5660/051 708 6724)

BMA East Anglian Regional Office, Mr David Morgan 10 Downing Street,

Cambridge CB2 3DS.

(tel: 0223 64539)

BMA Wessex Regional Office, 4 St Peter Street, Winchester SO23 8BW.

(tel: 0962 56760)

BMA South Western Regional Office, Mr Tudor Smith 151 Whiteladies Road, Clifton,

Bristol BS8 2RA.

(tel: 0272 736636/739677)

BMA Thames Regional Office, BMA House, Tavistock Square, London WC1H 9JP.

(tel: 01387 4499)

BMA Thames Regional Office.

BMA Thames Regional Office.

BMA Thames Regional Office.

Mr Tony Coley

Industrial relations officer

Mr J Milligan

Mr David Melvin

Mr Stuart Morgan

Mr Brian Richardson

Mr John Leach

Mrs Anne Cullinan

Mr J Graves 